\title{
Fungi isolated from cysts of the beet cyst nematode parasitized its eggs and counterbalanced root damages
}

\author{
Rasha Haj Nuaima $^{1,2} \cdot$ Samad Ashrafi ${ }^{1}\left[\right.$. Wolfgang Maier ${ }^{1} \cdot$ Holger Heuer $^{1}$
}

Received: 31 January 2020 / Revised: 29 May 2020 / Accepted: 8 June 2020 / Published online: 23 June 2020

(c) The Author(s) 2020

\begin{abstract}
Finding beneficial fungi antagonistic toward nematodes is important for developing more sustainable agricultural practices. We isolated abundant fungi from cysts of the beet cyst nematode Heterodera schachtii and tested their interaction with nematodes and sugar beet. By molecular screening of fungal communities colonizing five field populations of $H$. schachtii using DGGE and Sanger sequencing, three strains identified as Exophiala sp., Pochonia chlamydosporia and Pyrenochaeta sp. were frequently found in infected cysts and then specifically isolated (in pure culture). The three isolates were able to re-infect the cysts and colonize the eggs of $H$. schachtii in vitro fulfilling Koch's postulates. In greenhouse trials, the root weight of sugar beet plants grown in substrates inoculated with nematodes and the fungal isolates was significantly higher compared to plants inoculated with nematodes only. The number of cysts propagated on roots was lower in substrates inoculated with Pyrenochaeta sp. than those in substrates inoculated with the other two fungi. However, cyst numbers did not significantly differ from the control because the propagation rate of the nematode increased with the root weight. The proportion of infected eggs per cyst was higher under the fungal treatments than the control, and it increased with the number of propagated cysts. The results showed that the here-studied strains of Exophiala sp., Pochonia chlamydosporia and Pyrenochaeta sp. were frequently found colonizing the nematode cysts of different populations of $H$. schachtii and were efficient in parasitizing the eggs of the nematode.
\end{abstract}

Keywords Beet cyst nematode $\cdot$ Exophiala $\cdot$ Heterodera schachtii $\cdot$ Nematophagous fungi $\cdot$ Pochonia chlamydosporia . Pyrenochaeta

\section{Key message}

- Screening of the beet cyst nematode Heterodera schachtii for egg-parasitic fungi resulted in the isolation of three fungal strains of Exophiala sp. Pochonia chlamydosporia

Communicated by E. Quesada-Moraga.

Electronic supplementary material The online version of this article (https://doi.org/10.1007/s10340-020-01254-2) contains supplementary material, which is available to authorized users.

Samad Ashrafi

samad.ashrafi@julius-kuehn.de

1 Institute for Epidemiology and Pathogen Diagnostics, Julius Kühn-Institut, Federal Research Centre for Cultivated Plants, Messeweg 11-12, 38104 Braunschweig, Germany

2 Department of Plant Protection, Faculty of Agriculture, Euphrates University, Deir Ezzor, Syria and Pyrenochaeta sp. as the most frequent nematophagous fungi parasitizing the eggs of different populations of $H$. schachtii in North Rhine-Westphalia, Germany.

- The parasitism of isolates could be reproduced in in vitro and greenhouse studies.

- Inoculation of sugar beet plants with these fungi resulted in a significant plant development in nematode-infected plants suggesting further studies to investigate endophytic interaction between these strains with sugar beet within a tripartite interaction system including fungus -plant-plant parasitic nematode.

\section{Introduction}

The beet cyst nematode (BCN) Heterodera schachtii is a cyst-forming plant parasitic nematode causing considerable economic losses in sugar beet (Beta vulgaris) production (Müller 1999). Wide non-host rotations and the introduction 
of resistant cover crops besides the use of resistant sugar beet cultivars are the most common approaches to manage BCN (Müller 1999). These strategies might be either uneconomic or the resistance efficiency could be lost over time because the parasitism genes of nematodes are highly diverse and plant nematode resistance genes are still elusive (Griffin 1982). Population dynamics of plant parasitic nematodes (PPNs) are not only affected by changes in abiotic factors such as temperature and moisture but also by nematode antagonists living in the soil (Trivedi 2003). Cyst nematode populations can be suppressed by several antagonistic fungi, which are taxonomically diverse and are found throughout the kingdom of fungi. This group of fungi is capable of capturing and parasitizing nematodes (Nordbring-Hertz et al. 2011). A sub-group of these fungi named as egg parasites attacks the eggs and females of sedentary PPNs including cyst-forming nematodes and infects their host through individual hyphae or specialized infection structures like appressoria (Ashrafi et al. 2017; Lopez-Llorca et al. 2002; MorganJones et al. 1983, 1984).

The females of cyst nematodes are potential target to be attacked by nematophagous fungi. During nematode development, an immature female ruptures the roots, develops and becomes gravid, and later dies and becomes a cyst that can remain infective in soil for several years in the absence of a host plant. This process causes a long-term exposure of female and cyst nematodes to different egg-parasitic fungi (Dijksterhuis et al. 1994; Jansson and Lopez-Llorca 2004; Ashrafi et al. 2017). The most intensively studied egg-parasitic fungi are Pochonia chlamydosporia, Purpureocillium lilacinum, and several species within the genera of Metarhizium and Trichoderma (Kerry 1980; Siddiqui and Mahmood 1996; Stirling 2014).

Several of these fungi have been reported to have a multifunctional lifestyle within a tripartite interaction, in which the fungus lives as an endophyte of the host plant and a pathogen of nematodes or insects (Barelli et al. 2016; Schouten 2016). For example, some nematophagous fungi (e.g. representatives of Arthrobotrys, Lecanicillium lecanii, Pochonia chlamydosporia, and Purpureocillium lilacinum) had been reported to colonize the plant roots endophytically (Bordallo et al. 2002; Lopez-Llorca et al. 2002; Schouten 2016), and it had been shown that an endophytic isolate of $P$. chlamydosporia produces plant hormones, which promote plant growth and subsequently increase the tolerance level to nematodes (Schouten 2016).

In addition to the above-mentioned fungi, several other fungal species were reported to parasitize nematode eggs: strains of Exophiala pisciphila and Pyrenochaeta terrestris (Syn Setophoma terrestris) were frequently found colonizing eggs of Globodera rostochiensis (potato cyst nematode), Heterodera avenae (cereal cyst nematode) and Heterodera glycines (soybean cyst nematode) (Chen et al. 1996; Chen and Chen 2002; Dackman 1990; Dackman and NordbringHertz 1985). The genus Exophiala is diverse in ecology, and it includes several species frequently isolated from different hosts and natural environments, e.g. plant tissues, soil and water (Addy et al. 2005; Maciá-Vicente et al. 2016; Najafzadeh et al. 2013). The genus also accommodates species reported as plant endophytes. Wang et al. (2013) reported an endophytic strain of Exophiala salmonis isolated from the roots of Paris polyphylla. Recently, Maciá-Vicente et al. (2016) described the endophytic Exophiala radicis isolated from the roots of Microthlaspi perfoliatum.

In a previous study (Nuaima et al. 2019), the denaturing gradient gel electrophoresis (DGGE) analysis of the fungal community infecting the cysts of a field population showed the frequency of two fungi, Exophiala sp. and P. chlamydosporia. In the present study, during a molecular screening based on DGGE conducted to analyze the fungal community infecting the cysts of different field populations of $H$. schachtii in Germany, several fungal isolates were frequently found colonizing the cysts of $H$. schachtii. The fungi were isolated, and their antagonistic potential toward the nematode eggs was evaluated in in vitro and in greenhouse experiments. The objectives of the present study were therefore addressed to: (1) isolate the most frequent fungal strains colonizing different field populations of $H$. schachtii and (2) examine the biocontrol potential of the isolated fungi on $H$. schachtii in vitro and greenhouse trials.

\section{Materials and methods}

\section{Nematode collection and materials examined}

Cysts of the BCN H. schachtii were collected from soils of five sugar beet fields naturally infected with BCN, located in Lower Saxony and North Rhine-Westphalia in Germany (Table 1). The soil samples were taken at $0-30 \mathrm{~cm}$ depth from each of the sugar beet fields. The nematode cysts were extracted from the soil samples using a centrifugal floatation technique with $\mathrm{MgSO}_{4}$ solution of $1.28 \mathrm{~g} / \mathrm{cm}^{3}$ (Müller 1980). Representatives of cyst samples collected from all

Table 1 Coordinates of sugar beet fields located in North RhineWestphalia, Germany that represent the origin of $H$. schachtii populations processed in this study

\begin{tabular}{lll}
\hline Sugar beet fields & Coordinates & $\begin{array}{l}\text { Number of } \\
\text { samples }\end{array}$ \\
\hline Hottorf & $50.593005 \mathrm{~N}, 6.205978 \mathrm{E}$ & 29 \\
Kerpen-Blatzheim & $50.859300 \mathrm{~N}, 6.627100 \mathrm{E}$ & 4 \\
Euskirchen-Dom-Esch & $50.685500 \mathrm{~N}, 6.860600 \mathrm{E}$ & 6 \\
Titz-Kalrath & $50.975300 \mathrm{~N}, 6.450200 \mathrm{E}$ & 4 \\
Swisttal-Miel & $50.667000 \mathrm{~N}, 6.943200 \mathrm{E}$ & 6 \\
\hline
\end{tabular}


fields were screened for nematode infection by fungi. The symptomatic cyst samples collected from "Hottorf" were additionally used for fungal isolation.

\section{DNA extraction, PCR amplification, sequencing and DGGE analyses}

To extract genomic DNA of fungal strains colonizing cysts of $H$. schachtii, ten cysts of each soil sample were handpicked and collected in $1.5 \mathrm{ml}$ tubes containing $30 \mu \mathrm{l}$ of water. Cysts were crushed, and DNA was then extracted using the cell lysis buffer as described in detail by Nuaima et al. (2018). For culture-dependent species identification, fungal mycelium was obtained from the pure cultures grown on potato dextrose agar (PDA) and transferred to $1.5 \mathrm{ml}$ tubes. Fungal cells were mechanically disrupted and processed as described above. DNA was purified using the DNA Clean \& Concentrator Kit (Zymo Research, Freiburg, Germany) and used as a template for PCR amplification.

The internal transcribed spacers (ITS 1 and 2 region) including the 5.8S rDNA of the ribosomal gene cluster was amplified with primer sets ITS1f \& ITS4 (White et al. 1990) and ITS1f-GC \& ITS2 with a GC tail specific for denaturing gradient gel electrophoresis (DGGE) according to Rungis (2015). The long PCR-amplified ITS fragments with sizes of 450-750 bp were purified using a High Pure PCR Product Purification Kit (Merck, Darmstadt, Germany) following the manufacturer's instructions, and sequenced by Macrogen Europe (Amsterdam, The Netherlands) with primers ITS1f and ITS4. The obtained sequences were assembled with Sequencher 5.4.1 (Gene Codes Corporation, Ann Arbor, Michigan, USA) and deposited in GenBank under the following accession numbers: MN537134-MN537137. The sequences generated were compared with the publically available sequences in GenBank using a BLASTn search for a preliminary DNA-based identification.

The short ITS1 fragments amplified with ITS1f-GC and ITS2 with about 250 bp were used for DGGE as recently described (Nuaima et al. 2019). The ITS1 fragments were PCR-amplified from the cloned and sequenced ITS fragments of Exophiala sp. and P. chlamydosporia (Nuaima et al. 2019) and used as references in DGGE analysis.

\section{Isolation of fungi from symptomatic cysts of $\boldsymbol{H}$. schachtii}

Field-collected cyst samples (Hottorf Germany) were examined under an Olympus SZX 12 dissecting microscope to handpick the cysts displaying symptoms of fungal infection like discernible fungal hyphae or discolored eggs. The selected symptomatic cysts were surface sterilized in $0.5 \%$ sodium hypochlorite $(\mathrm{NaOCl})$ for $10 \mathrm{~min}$ following three washes with distilled water. The surface-sterilized cysts were individually placed onto potato dextrose agar (PDA, Carl Roth GmbH, Germany) supplemented with penicillin G $(240 \mathrm{mg} / \mathrm{L})$ and streptomycin sulfate $(200 \mathrm{mg} / \mathrm{L})$. Plates were incubated at room conditions and monitored regularly. To purify the obtained isolates, fungal mycelia growing from the cultured cysts were subcultured on new PDA plates. Pure cultures obtained were initially grouped based on their morphological criteria and later were also processed for DNAbased identification.

\section{In vitro pathogenicity tests of the fungal isolates toward nematode eggs}

Healthy-looking gravid females and cysts extracted from a greenhouse-propagated population (Gross Munzel, Germany) were surface sterilized as described above. The fungal isolates of interest (Ex007, Pc001, Py004) obtained in this study were grown on PDA for up to 1 month in five replicates. Ten surface-sterilized healthy cysts were placed on top of each of the fungal colonies and incubated at room conditions. Incubated cysts were microscopically monitored at regular intervals for fungal infection. Cysts placed on blank PDA were considered as the control treatment.

To examine pathogenicity of fungal isolates of interest toward nematode females, 6 weeks-old gravid females were extracted from roots, washed with sterilized distilled water, and incubated on fungal colonies. A sterility check was done prior to incubation by imprinting the females into PDA.

\section{Pathogenicity tests against $H$. schachtii in vivo}

Pot experiments were conducted to assess the biocontrol potential of the fungal strains against $H$. schachtii. Autoclaved-sterilized loess soil (Müller and Rumpenhorst 2000) enriched with slow-release fertilizer (Osmocote Exact Standard ${ }^{\circledR}$ ) at a rate of $1.25 \mathrm{~g} / \mathrm{kg}$ was used as the substrate. Two-month-old PDA cultures of the fungal isolates were used for the experiments. Pots $(500 \mathrm{ml})$ were inoculated with 15 plugs ( $5 \mathrm{~mm}$ in diam.) of either one fungal isolate or a mixture of two isolates. In total, the treatments were as follows: (1) isolate Ex007, (2) isolate Pc001, (3) isolate Py004, (4) isolates Ex007 + Pc001, and (5) untreated control. Each treatment was replicated 15 times. Control treatments consisted of pots inoculated with plugs of non-fungal colonized PDA. Pots were placed in a greenhouse and incubated for 1 week to allow the fungi to establish in the soil. Pots were then sown with a nematode susceptible sugar beet cultivar "Beretta." Two weeks later, each plant was inoculated with 2500 freshly hatched second-stage juveniles (J2) from the greenhouse-propagated cysts of $H$. schachtii. The plants were grown at $16 / 20^{\circ} \mathrm{C}$ with a 16 -h photoperiod for 8 months to obtain four nematode generations. 
Fresh shoots were removed, and the roots were left for 2 weeks more in the pots to allow full development/maturation of the cysts. Roots were gently removed from the soil and rinsed until no soil debris was left. The fresh weight of each root sample was recorded. Nematode cysts were extracted by washing the entire soil of each pot through a $250-\mu \mathrm{m}$ sieve and counted under a stereo microscope. To record the number of fungal infected eggs, the cysts of each treatment were pooled and a sub-sample consisting of 1000 cysts was processed. The cysts were squashed using a tissue grinder for $30 \mathrm{~s}$ (IKA ${ }^{\circledR}$-Werke GmbH \& Co. KG, Staufen, Germany) to collect the eggs. Eggs were counted, and the mean numbers of eggs per cyst were calculated and reported. The infected eggs and cysts were photographed using light microscopy as described by Ashrafi et al. (2017).

\section{Data analysis}

Using the R software, the data describing the root weight, the propagated cysts and the infected eggs were analyzed by generalized linear models.

\section{Results}

\section{Frequency of cyst colonizing fungi}

The presence of fungi in cysts was assessed for cyst samples collected from five sugar beet fields located in North Rhine-Westphalia. From the field site "Hottorf," 29 PCRamplified ITS fragments, each representing the fungi colonizing cysts of $H$. schachtii was analyzed using DGGE. Each of the resolved patterns was unique, and thus the fungal communities infecting the cysts were different among the 29 ITS patterns. Nevertheless, four ITS bands were highly frequent among all 29 patterns, and two out of the four were identical to the fungal clones of Exophiala sp. and P. chlamydosporia in their electrophoretic mobility in DGGE (Supplementary Fig. 1). The ITS patterns for the fungi infecting the cysts extracted from the other four field populations of $H$. schachtii were different within and among the nematode populations. The most frequent two ITS bands were identical in their electrophoretic mobility to the ITS clones of Exophiala sp. and P. chlamydosporia (Supplementary Fig. 2).

\section{Fungal isolation}

Four fungal strains were isolated from the cyst samples collected from Hottorf. The BLASTn search of the ITS sequences of the isolates revealed relatedness of the obtained fungal strains to the genera Exophiala, Fusarium, Pochonia and Pyrenochaeta: The fungal strains EX007 and Py004 showed high sequence similarity with $99 \%$ and $100 \%$ to the endophytic strains reported from the genera of Exophiala and Pyrenochaeta, respectively. The strain Fu010 was identified/grouped as a Fusarium species and was not included in further experiments. The strain Pc001 was identified as $P$. chlamydosporia, which was also supported by morphological examinations of the pure cultures (Supplementary Fig. 3).

\section{In vitro parasitism of fungal strains toward nematode eggs}

The fungal strains Ex007, Pc001, and Py004 were capable of colonizing the cysts and infecting the eggs of $H$. schachtii in vitro. The strains Ex007 (Exophiala sp.) and Py004 (Pyrenochaeta sp.) rendered incubated cysts discolored. The symptomatic cysts contained eggs, which were fully colonized and rendered light to dark brownish appearance (Fig. 1d, g). The fungal isolate Ex007 parasitized and discolored gravid females 1 week after incubation (Fig. 1b). Strain Pc001 (P. chlamydosporia) infected the nematode eggs and destroyed the embryonic juveniles (Fig. 1i); however, neither the infected cysts nor the colonized eggs had a discolored appearance. The sterility check revealed no fungal growth from the examined cysts.

\section{Greenhouse experiments}

\section{The effect of fungi on plant growth}

The plant roots treated with the here-studied fungal strains developed significantly better in comparison with the control treatment (non-fungal treated) in the presence of the nematodes (Fig. 2a-e, f). Among the four fungal treatments, the root weight did not differ significantly (Fig. 2f).

\section{Correlation between number of propagated cysts and root weight}

For all treatments, the population density of propagated cysts was positively correlated with the root weight (Fig. 3a). When the root weights in the treatments of Ex007 (Exophiala sp.), Pc001 (P. chlamydosporia), and Ex007+ Pc001 (Exophiala sp. plus $P$. chlamydosporia) were significantly higher than the control, the number of cysts was also significantly higher in these fungal treatments than in the control (Fig. 3b). However, the number of cysts did not significantly differ between the treatments of Py004 (Pyrenochaeta sp.) and control (Fig. 3b).

\section{Parasitic potential toward nematode eggs}

All fungal isolates could parasitize nematode eggs in the greenhouse. The number of infected eggs per cyst was 

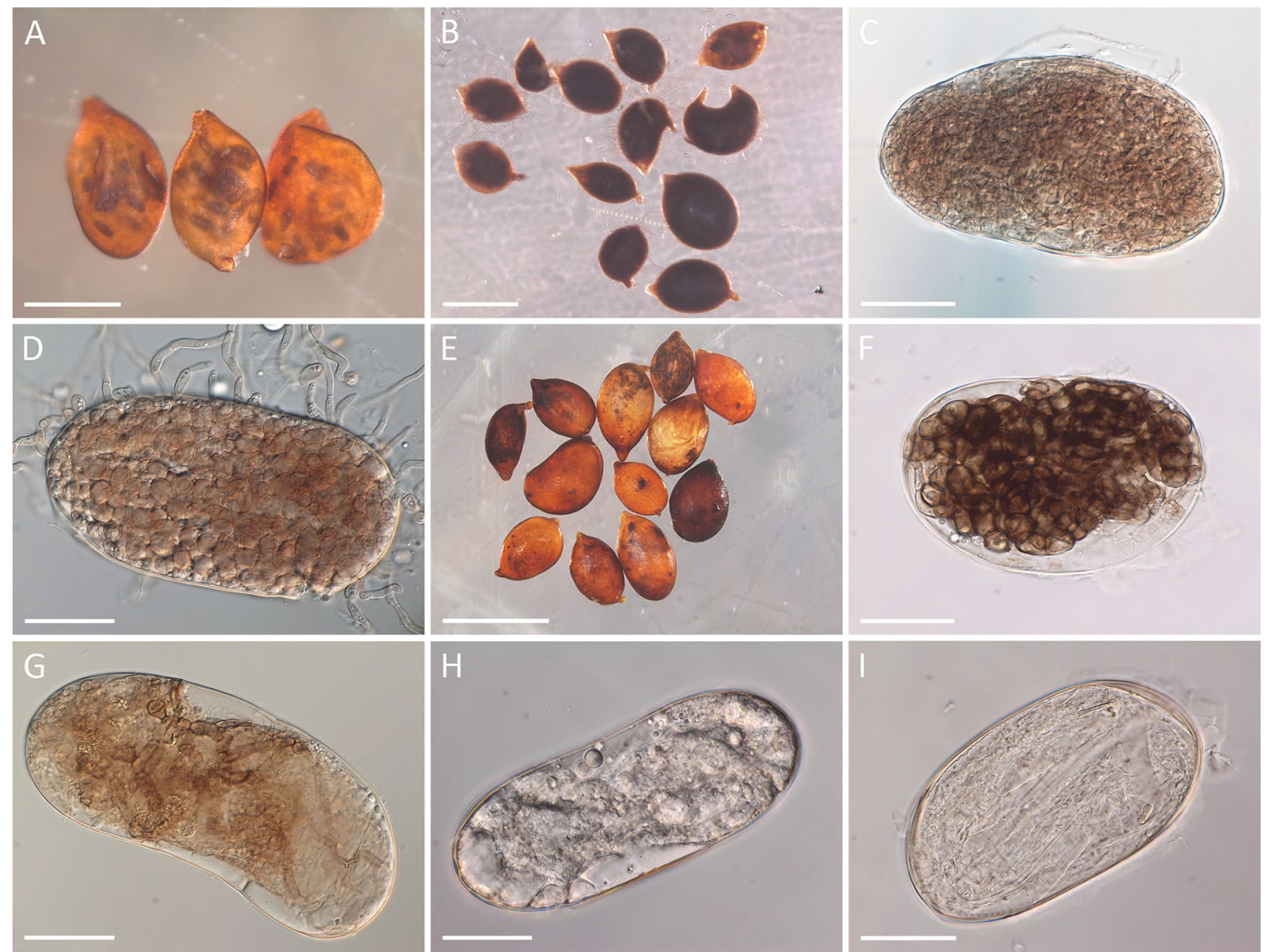

Fig. 1 The isolates of Exophiala sp., Pyrenochaeta sp., and Pochonia chlamydosporia infected cysts and colonized eggs of $H$. schachtii in laboratory and greenhouse trials. a Infected cysts with Exophiala sp. from greenhouse trials. b Infected gravid females with Exophiala sp. from in vitro trials. c Infected egg with Exophiala sp. from greenhouse trials. d Egg infected by Exophiala sp. from in vitro trials. e
Cysts infected with Pyrenochaeta sp. from greenhouse trials. f Egg infected with Pyrenochaeta sp. from greenhouse trials. $\mathbf{g}$ Egg infected by Pyrenochaeta sp. from in vitro trials. h Egg infected with $P$. chlamydosporia from greenhouse trials. i Egg infected with $P$. chlamydosporia from in vitro trials similar among the four fungal treatments (Fig. 4a). Under the fungal treatments of Ex007, Pc001, and Py004, high proportions of infected eggs were isolated (Fig. 1c, f, h). The infected cysts extracted from the fungal treatments of Ex007 and Py004 displayed a discolored appearance (Fig. 1a, e). The number of infected eggs per cyst was similar among the four fungal treatments (Fig. 4a). The microscopic examination and the data analysis showed that the proportion of infected/discolored eggs was higher under the fungal treatments than in the control (Fig. 4a). A significant positive correlation was apparent between the number of infected eggs and the number of cysts under the experimental treatments (Fig. 4b).

\section{Discussion}

The fungal isolates Exophiala sp.(strains Ex007), P. chlamydosporia (strain Pc001), and Pyrenochaeta sp. (strain Py004) were found to frequently parasitize the eggs of $H$. schachtii during this study. The ability of Exophiala and Pochonia species to parasitize the eggs of $H$. schachtii (Chen and Chen 2003; Kerry 2000) could explain the high prevalence of these colonizers inside the cysts originating from different populations in this study (see Supplementary Figs. 1 and 2). The fungal strain of Pyrenochaeta sp. was also frequently found colonizing the nematode cysts, 

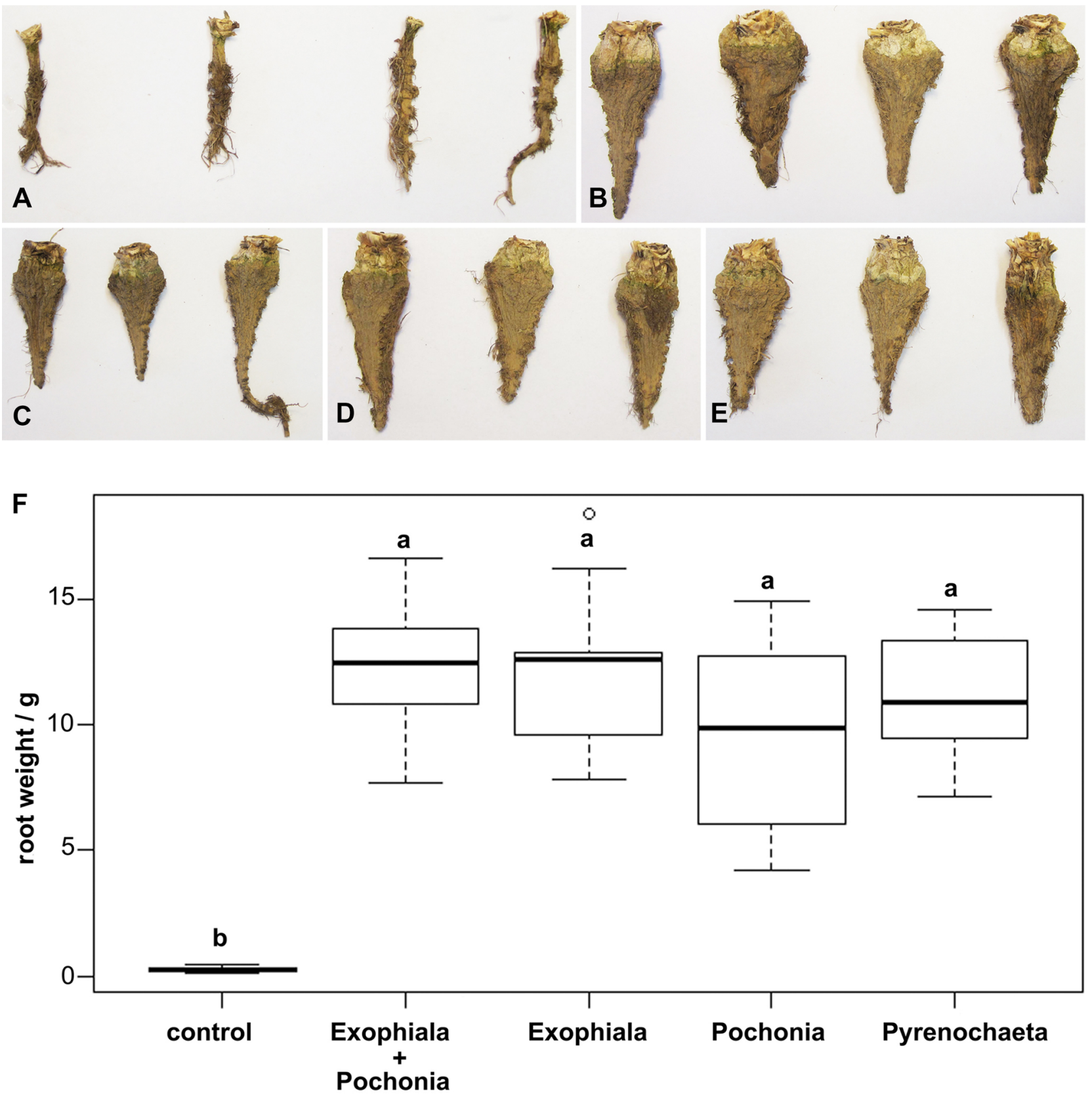

Fig. 2 Effects of fungal strains on plant growth in the presence of nematode. a Sugar beet roots grown in substrates inoculated only with nematodes under the control treatment. b Sugar beet roots grown in substrates inoculated with nematodes and Exophiala sp. and Pochonia chlamydosporia. c Sugar beet roots grown in substrates inoculated with nematodes and Exophiala sp. d Sugar beet roots grown in substrates inoculated with nematodes and P. chlamydospo-

where four out of ten isolates extracted from the cysts of $H$. schachtii were identified as Pyrenochaeta sp. suggesting a high parasitic potential of this strain toward $H$. schachtii. Parasitism of Pyrenochaeta against other plant parasitic nematodes was already reported for $P$. terrestris ria. e Sugar beet roots grown in substrates inoculated with nematodes and Pyrenochaeta sp. f Box plots calculated for root weight of sugar beet planted for 8 months to obtain four nematode generations under four fungal and a control treatments. Different letters indicate significant differences in root weight among treatments (Dunn test, $P<0.05$, $n=15$ )

isolated from the soybean cyst nematode, Heterodera glycines showing a high rate of egg parasitism (Chen et al. 1996). The pathogenicity tests revealed that these fungi parasitized the females of the nematode. The parasitic ability of the fungi might be higher on the gravid females than 

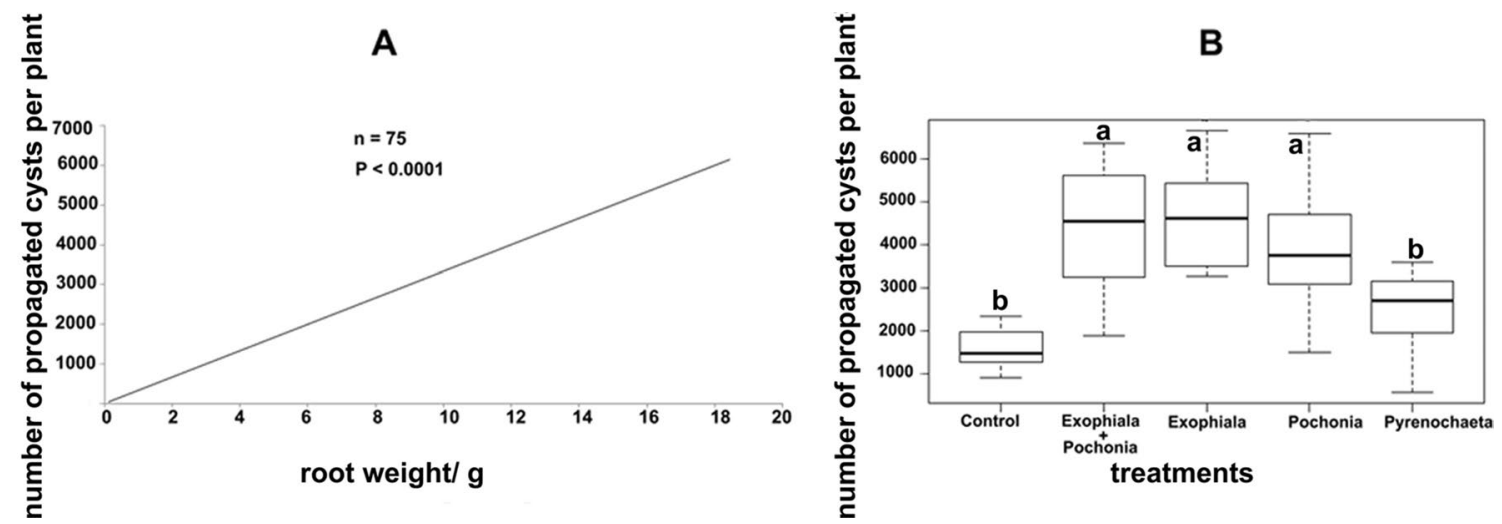

Fig. 3 Correlation between number of propagated cysts and root weight. a Regression lines of propagated cysts of Heterodera schachtii with respect to the root weight of sugar beet planted under fungal and control treatments ( $T$-Test, $P$-values calculated at $95 \%$ confidence level, number of pairwise combination is indicated by $n$ ). b Box plots for numbers of cysts of $H$. schachtii at Gross Munzel that propagated for four generations on sugar beet under the fungi and control treatments. Different letters indicate significant differences in numbers of propagated cysts among treatments (Dunn test, $P<0.05$, $n=15)$

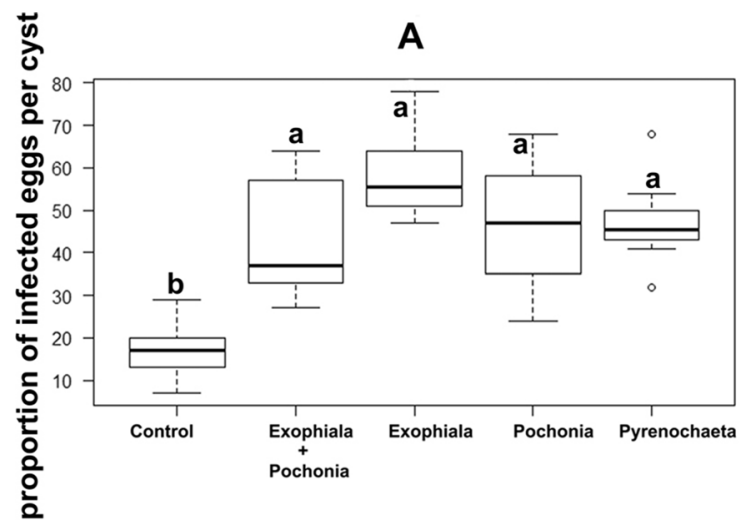

Fig. 4 Parasitic potential of fungal strains toward nematode eggs. a Box plots for the proportion of infected eggs per cyst of Heterodera schachtii at Gross Munzel that propagated for four generations on sugar beet under fungal and control treatments. Different letters indicate significant differences in numbers of propagated cysts among

on old cysts because the body wall of the gravid females is not hardened enough to protect the eggs. This can give the opportunity for the fungal parasites to attack the eggs faster (Cayrol et al. 1982; Kerry and Irving 1986).

In this experiment, cysts were not used as nematode inoculum because of the relatively high variability of egg numbers and hatching rate. The initial infection of the cysts by the fungi of interest is expected to affect the nematode hatching process, which could consequently increase the variability of the number of juveniles hatched from the infected cysts. This would then affect the final evaluation of the nematicidal activity of the target isolates.

Surprisingly, the results of this research showed that the roots of sugar beet infected with $H$. schachtii were significantly larger in fungal-treated plants compared to the control

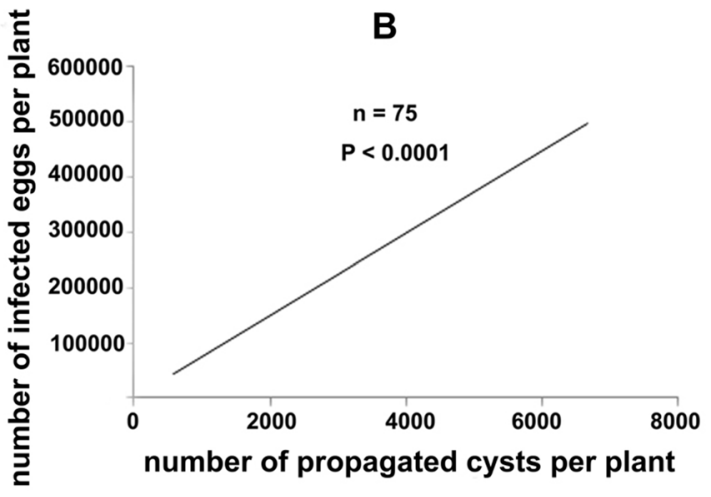

treatments (Dunn test, $P<0.05, n=15$ ). b Regression line of infected eggs of $H$. schachtii with respect to the number of propagated cysts ( $T$-Test, $P$-values calculated at $95 \%$ confidence level, number of pairwise combination is indicated by $\mathrm{n}$ )

without fungi. These effects might have been caused directly by the fungi reducing the nematode numbers in the early phases of root growth, thus reducing their negative impact on the development of the roots. Indirect effects like plant growth promotion or inducing the plant immune defense against the nematodes might have also played a role in case the fungi are able to colonize the plant roots endophytically, but were not studied here.

Nevertheless, the ITS sequences of the isolates of Exophiala sp. and Pyrenchaeta sp. were highly similar to the endophytic fungi isolated from Paris polyphylla and Microthlaspi spp., respectively (Glynou et al. 2016; Wang et al. 2013). In culture, they developed darkly pigmented and septate hyphae, which are characteristic features for dark septate endophytes (DSE). Dark septate 
endophytes are ubiquitous fungi reported from the roots of a wide range of host plants and habitats (Jumpponen and Trappe 1998; Rodriguez et al. 2009). Recently, Ashrafi et al. (2018) for the first time reported a DSE parasitizing eggs of a plant parasitic nematode, namely the cereal cyst nematode Heterodera filipjevi. The ecological role that this group of fungi plays is not well understood. However, their mutualistic interaction with the plant hosts has been frequently reported (Mandyam et al. 2010; Newsham et al. 2009).

Some endophytic fungi were shown to produce plant hormones, which can mediate plant growth (Aly et al. 2011; Tan and Zou 2001). For example, the auxins produced by the endophytes Trichoderma virens or T. atroviride increased the biomass and accelerated the root development of Arabidopsis thaliana seedlings (Contreras-Cornejo et al. 2009). Recently, an endophytic isolate of the nematophagous $P$. chlamydosporia was reported to produce indol acetic acid (IAA) that promoted root growth (Schouten 2016). The fungal strains EX007 and Py004 need to be studied for further identification, but given their sequence similarity to reported endophytic strains they might play a role as endophytic fungi in enhancing plant growth and increasing the biomass. It can be hypothesized that these strains might produce a set of metabolites, which could be involved in plant growth via growth mediation, induced resistance or nematicidal activity.

The number of propagated cysts of $H$. schachtii increased with increasing biomass of plant roots. In fact, the increase of the root branching leads to an increase of potential infection sites (Curtis et al. 2009; Schouteden et al. 2015). On the other hand, the increase in root growth leads to an increase of nutrient uptake, which compensates the reduction in the root growth caused by nematode infection (Schouteden et al. 2015). This might explain the correlation between the number of cysts and root biomass we observed during this study. Cyst formation on the root colonized by endophytic nematode parasitic fungi may provide nutrition sources for those fungi (Jansson and Lopez-Llorca 2004). Therefore, the limitation in the numbers of females will limit the presence of fungal parasites (Kerry et al. 1982; Lopez-Llorca and Boag 1993). This concept could explain the positive correlation between the ratio of egg infection and the number of propagated cysts.

Under the fungal treatments in this study, fungal inoculated plants developed larger roots. This could potentially provide more feeding sites for the nematodes, which might lead to reproduction of more consecutive generations and subsequently lead to higher final nematode populations. However, the density of infected eggs increased by increasing nematode numbers. The same observations were made by Lopez-Llorca and Boag (1993), who found higher numbers of $H$. avenae juveniles in roots inoculated with $P$. chlamydosporia than in non-treated controls.
Fungi parasitic to plant parasitic nematodes may in future considerably contribute to a more sustainable agriculture. Screening for beneficial fungi antagonistic to plant parasitic nematodes should consider the ability for mass production of these fungi (Schouten 2016). The three isolated fungal strains infecting populations of $H$. schachtii were culturable and efficiently parasitized the eggs of $H$. schachtii. Consequently, the fungal isolates of Exophiala, P. chlamydosporia and Pyrenochaeta could be promising candidates to reduce the impact of $H$. schachtii on sugar beet.

To increase the efficiency of the fungal parasitism toward plant parasitic nematodes, the variety of the host plant has to be taken into account (Stirling 2014). On susceptible varieties, the rate of nematode reproduction will be high, especially for those species having a life cycle with several generations per season like $H$. schachtii, which can produce 3-4 generations in a growing season. This high multiplication rate tends to negate the effects of antagonists, as high levels of parasitism and predation may remove surplus nematodes but do not diminish the final nematode numbers (Stirling 2014). Using tolerant plant cultivars besides the biological control agent is therefore of importance to have a sustainable management of the plant parasitic nematodes (Stirling 2014). In this respect, identifying fungi that parasitize the eggs of $H$. schachtii and have beneficial on the root growth might be especially promising to develop a sustainable management of this plant parasitic nematode.

\section{Author contribution}

RHN: Performing the molecular assay, laboratory and greenhouse trials, analyzing and interpreting the data of the work, writing the original draft. SA: Contribution to the design and the laboratory work, reviewing and editing the writing. WM: reviewing and editing the writing. HH: Substantial contributions to the conception and design of the work, reviewing and editing the writing.

Acknowledgements Open Access funding provided by Projekt DEAL. The authors thank Dr. Matthias Daub and Johannes Roeb (Julius Kühn Institut/Elsdorf and Münster) for providing the field soil samples.

Funding RHN was financed by the German Research Foundation (DFG) grant HE6957/1-1.

Data availability statement All data and fungal strains of this study are available on request.

\section{Compliance with ethical standards}

Conflicts of interest The authors declare that they have no conflict of interest. 
Ethical approval This research does not contain any studies with human participants and/or animals.

Informed consent Informed consent was obtained from all co-authors included in this study.

Open Access This article is licensed under a Creative Commons Attribution 4.0 International License, which permits use, sharing, adaptation, distribution and reproduction in any medium or format, as long as you give appropriate credit to the original author(s) and the source, provide a link to the Creative Commons licence, and indicate if changes were made. The images or other third party material in this article are included in the article's Creative Commons licence, unless indicated otherwise in a credit line to the material. If material is not included in the article's Creative Commons licence and your intended use is not permitted by statutory regulation or exceeds the permitted use, you will need to obtain permission directly from the copyright holder. To view a copy of this licence, visit http://creativecommons.org/licenses/by/4.0/.

\section{References}

Addy HD, Piercey MM, Currah RS (2005) Microfungal endophytes in roots. Can J Bot 83:1-13. https://doi.org/10.1139/b04-171

Aly AH, Debbab A, Proksch P (2011) Fungal endophytes: unique plant inhabitants with great promises. Appl Microbiol Biotechnol 90:1829-1845. https://doi.org/10.1007/s00253-011-3270-y

Ashrafi S, Helaly S, Schroers H-J, Stadler M, Richert-Pöggeler KR, Dababat AA, Maier W (2017) Ijuhya vitellina sp. nov., a novel source for chaetoglobosin A, is a destructive parasite of the cereal cyst nematode Heterodera filipjevi. PLoS ONE 12:e0180032. https://doi.org/10.1371/journal.pone.0180032

Ashrafi S, Knapp DG, Blaudez D, Chalot M, Maciá-Vicente JG, Zagyva I, Dababat AA, Maier W, Kovács GM (2018) Inhabiting plant roots, nematodes, and truffles-, a new helotialean genus with two globally distributed species. Mycologia 110:286-299

Barelli L, Moonjely S, Behie SW, Bidochka MJ (2016) Fungi with multifunctional lifestyles: endophytic insect pathogenic fungi. Plant Mol Biol 90:657-664. https://doi.org/10.1007/s11103-015-0413-z

Bordallo JJ, Lopez-Llorca LV, Jansson H-B, Salinas J, Persmark L, Asensio L (2002) Colonization of plant roots by egg-parasitic and nematode-trapping fungi. New Phytol 154:491-499. https://doi. org/10.1046/j.1469-8137.2002.00399.x

Cayrol JC, Velasquez-Dominguez M, Levaux P (1982) Etude préliminaire sur les possibilityés \& d'utilisation des champignons parasites comme agents de lutte biologique1. EPPO Bull 12:497-503. https://doi.org/10.1111/j.1365-2338.1982.tb01835.x

Chen F, Chen S (2002) Mycofloras in cysts, females, and eggs of the soybean cyst nematode in Minnesota. Appl Soil Ecol 19:35-50. https://doi.org/10.1016/S0929-1393(01)00179-2

Chen SY, Chen FJ (2003) Fungal parasitism of Heterodera glycines eggs as influenced by egg age and pre-colonization of cysts by other fungi. J Nematol 35:271-277

Chen S-Y, Dickson DW, Mitchell DJ (1996) Population development of Heterodera glycines in response to mycoflora in soil from Florida. Biol Control 6:226-231

Contreras-Cornejo HA, Macías-Rodríguez L, Cortés-Penagos C, López-Bucio J (2009) Trichoderma virens, a plant beneficial fungus, enhances biomass production and promotes lateral root growth through an auxin-dependent mechanism in Arabidopsis. Plant Physiol 149:1579-1592. https://doi.org/10.1104/ pp.108.130369
Curtis RHC, Robinson AF, Perry RN (2009) Hatch and host location. In: Perry RN, Moens M, Starr JL (eds) Root-knot nematodes. CABI North American Office, Cambridge, pp 139-162

Dackman C (1990) Fungal parasites of the potato cyst nematode Globodera rostochiensis: isolation and reinfection. J Nematol 22:594-597

Dackman C, Nordbring-Hertz B (1985) Fungal parasites of the cereal cyst nematode Heterodera avenae in Southern Sweden. J Nematol 17:50-55

Dijksterhuis J, Veenhuis M, Harder W, Nordbring-Hertz B (1994) Nematophagous fungi: physiological aspects and structure-function relationships. Adv Microb Physiol 36:111-143

Glynou K, Ali T, Buch A-K, Haghi Kia S, Ploch S, Xia X, Çelik A, Thines M, Maciá-Vicente JG (2016) The local environment determines the assembly of root endophytic fungi at a continental scale. Environ Microbiol 18:2418-2434. https://doi. org/10.1111/1462-2920.13112

Griffin GD (1982) Differences in the response of certain weed host populations to Heterodera schachtii. J Nematol 14:174-182

Jansson H-B, Lopez-Llorca LV (2004) Control of nematodes by fungi. In: Arora DK, Bhatnagar D, Bridge PD (eds) Fungal biotechnology in agricultural, food, and environmental applications, vol 20031564. Marcel Dekker, New York

Jumpponen A, Trappe JM (1998) Dark septate endophytes: a review of facultative biotrophic root- colonizing fungi. New Phytol 140:295-310

Kerry B (1980) Biocontrol: fungal parasites of female cyst nematodes. J Nematol 12:253-259

Kerry BR (2000) Rhizosphere interactions and the exploitation of microbial agents for the biological control of plant-parasitic nematodes. Annu Rev Phytopathol 38:423-441. https://doi. org/10.1146/annurev.phyto.38.1.423

Kerry BR, Irving F (1986) Variation between strains of the nematophagous fungus, verticillium chlamydosporium Goddard. Ii. Factors affecting parasitism of cyst nematode eggs. Nematology 32:474485. https://doi.org/10.1163/187529286X00345

Kerry BR, Crump DH, Mullen LA (1982) Studies of the cereal cystnematode, Heterodera avenae under continuous cereals, 19741978. I. Plant growth and nematode multiplication. Ann Appl Biol 100:477-487. https://doi.org/10.1111/j.1744-7348.1982. tb01414.x

Lopez-Llorca LV, Boag B (1993) A contribution to the ecology of fungi associated with females and cysts of Heterodera avenae in Eastern Scotland. Nematol Mediterr 187-197

Lopez-Llorca LV, Olivares-Bernabeu C, Salinas J, Jansson H-B, Kolattukudy PE (2002) Pre-penetration events in fungal parasitism of nematode eggs. Mycol Res 106:499-506. https://doi.org/10.1017/ s0953756202005798

Maciá-Vicente JG, Glynou K, Piepenbring M (2016) A new species of Exophiala associated with roots. Mycol Prog 15:1. https://doi. org/10.1007/s11557-016-1161-4

Mandyam K, Loughin T, Jumpponen A (2010) Isolation and morphological and metabolic characterization of common endophytes in annually burned tallgrass prairie. Mycologia 102:813-821. https ://doi.org/10.3852/09-212

Morgan-Jones G, White JF, Rodriguez-Kabana R (1983) Phytonematode pathology: ultrastructural studies. I. Parasitism of Meloidogyne arenaria eggs by Verticillium chlamydosporium. Nematropica 13:245-260

Morgan-Jones G, White JF, Rodriguez-Kabana R (1984) Phytonematode pathology: ultrastructural studies. II. Parasitism of Meloidogyne arenaria eggs and larvae by Paecilomyces lilacinus. Nematropica 14:57-71

Müller J (1980) Ein verbessertes Extraktionsverfahren für Heterodera schachtii. Nachrichtenbl Deut Pflanzenschutzd 32:21-24 
Müller J (1999) The economic importance of Heterodera schachtii in Europe. Helminthologia 36:205-213

Müller J, Rumpenhorst HJ (2000) Prüfung von Kulturpflanzen auf Resistenz gegen pflanzenparasitäre Nematoden: testing of crop cultivars for resistance to plant parasitic nematodes. Mitteilungen aus der Biologischen Bundesanstalt für Land- und Forstwirtschaft Berlin-Dahlem, vol 372. Parey, Berlin

Najafzadeh MJ, Dolatabadi S, Saradeghi Keisari M, Naseri A, Feng P, de Hoog GS (2013) Detection and identification of opportunistic Exophiala species using the rolling circle amplification of ribosomal internal transcribed spacers. J Microbiol Methods 94:338342. https://doi.org/10.1016/j.mimet.2013.06.026

Newsham KK, Upson R, Read DJ (2009) Mycorrhizas and dark septate root endophytes in polar regions. Fungal Ecol 2:10-20. https://doi. org/10.1016/j.funeco.2008.10.005

Nordbring-Hertz B, Jansson H-B, Tunlid A (2011) Nematophagous Fungi. In: Encyclopedia of life sciences, vol 142. Wiley

Nuaima R, Roeb J, Hallmann J, Daub M, Otte S, Heuer H (2018) Effector gene vapl based DGGE fingerprinting to assess variation within and among Heterodera schachtii populations. J Nematol 50:517-528. https://doi.org/10.21307/jofnem-2018-055

Nuaima RH, Heuer H, Westphal A (2019) Effects of cover cropping on microbial communities associated with Heterodera schachtii and nematode virulence. Soil Syst 3:67. https://doi.org/10.3390/ soilsystems 3040067

Rodriguez RJ, White JF, Arnold AE, Redman RS (2009) Fungal endophytes: diversity and functional roles. New Phytol 182:314-330. https://doi.org/10.1111/j.1469-8137.2009.02773.x

Rungis D (2015) Microbiological and genetic analysis of fungi in discoloured silver birch (Betula pendula Roth) wood. Acta Biol Univ Daugavp 15:37-46
Schouteden N, de Waele D, Panis B, Vos CM (2015) Arbuscular mycorrhizal fungi for the biocontrol of plant-parasitic nematodes: a review of the mechanisms involved. Front Microbiol. https://doi. org/10.3389/fmicb.2015.01280

Schouten A (2016) Mechanisms involved in nematode control by endophytic fungi. Annu Rev Phytopathol 54:121-142. https:// doi.org/10.1146/annurev-phyto-080615-100114

Siddiqui ZA, Mahmood I (1996) Biological control of plant parasitic nematodes by fungi: a review. Bioresour Technol 58:229-239. https://doi.org/10.1016/S0960-8524(96)00122-8

Stirling GR (2014) Biological control of plant parasitic nematodes, $2^{\text {nd }}$. Soil ecosystem management in sustainable agriculture. $C A B$ International, Wallingford

Tan RX, Zou WX (2001) Endophytes: a rich source offunctional metabolites. Nat Prod Rep 18:448-459

Trivedi PC (ed) (2003) Nematode management in plants. Scientific Publ, Jodhpur

Wang Q, Shen S-K, Zhang A-L, Wu C-Y, Wu F-Q, Zhang X-J, Wang Y-H (2013) Isolation and diversity analyses of endophytic fungi from Paris polyphylla var. yunnanensis. Zhongguo Zhong Yao Za Zhi 38:3838-3844

White TJ, Bruns T, Lee S, Taylor J (1990) Amplification and direct sequencing of fungal ribosomal RNA genes for phylogenetics. PCR Protoc Guide Methods Appl 18:315-322

Publisher's Note Springer Nature remains neutral with regard to jurisdictional claims in published maps and institutional affiliations. 